\title{
Some promising sources of expansion of the introduction potential of Prunus pumila L.
}

\author{
Mikhail Lezin ${ }^{1 *}$, and Nikolai Glaz ${ }^{2}$ \\ ${ }^{1}$ Central Siberian Botanical Garden, Novosibirsk, Russia \\ ${ }^{2}$ Federal State Budgetary Scientific Institution "Ural Federal Agrarian Scientific Research Centre, \\ Ural Branch of the Russian Academy of Sciences", Ekaterinburg, Russia
}

\begin{abstract}
Prunus pumila $\mathrm{L}$ is an introduction species that is well cultivated in the steppe regions of Russia and is used as a rootstock for plums and apricots and less often as an independent fruit crop. The cultivation efficiency is reduced due to instability to rotting in regions with higher snow cover. The species naturally spread in North America, where it is represented by several varieties that differ in morphological characters. Representatives of var. susquehanae Willd. spread on acidic substrates and sometimes occur in wetlands and probably can increase the adaptive potential of the introduction population. According to the characteristic feature of this species is the dense short pubescence of young twigs, 2 genotypes were identified in the introduction population, probably representing descendants of var. susquehanae. These genotypes are valuable for further introduction studies in regions with problems in the cultivation of the species due to plant rotting.
\end{abstract}

\section{Introduction}

Prunus pumila L. A is a North American species that has been successfully spreads in Russia in the steppe territories of the Povolzhye, Ural and Siberia. The species is widely used in nurseries as a rootstock for plums and apricots, rarely represented in private horticulture as an independent fruit crop. The wider distribution of the species in Central Russia, the more northern regions and regions of industrial horticulture is hampered by instability to rotting, due to the lack of plasticity of the species.

The species $P$. pumila naturally spread in different climatic conditions of the United States and Canada, where it is represented of 4 varieties with met and overlapped slinghtly geographical ranges (P. pumila var. depressa Pursh., var. pumila L., var. susquehanae Willd., var. besseyi (L.H. Bailey) Gleason). Many foreign researchers have noted, that the four sand cherry taxa are not equally distinct [1, 2, 3, 4, 5]. Catling R.M. (1999) and Weakley A.S. (2005) consider var. susquehanae, as an independent species [1.4]. They are based on the most distinctive features: short pubescence of young twigs and spread on acidic soils. Sterility of the artificially produced hybrid var. susquehanae $\times$ var. depressa proves that var. susquehanae Willd. is a separate species [6].

\footnotetext{
${ }^{*}$ Corresponding author: Lezin-misha@mail.ru
} 
In studies, Rohrer J. R. (2000) demonstrated the almost continuous variability of the complex of diagnostic morphological characters, including the short pubescence of young twigs, in the complex of North American dwarf cherries [2]. He noted that among the var. susquehanae are marked specimens with completely glabrous and at the same time, in several cases, a sparse sparse pubescent was detected in samples from the other three specimens. Based on this study, Rohrer (2000) and Bragg D. C. (2004) recognize at the species level or, given other environmental conditions for growth, may agree to the recognition of subspecies status for susquehanae [2,3].

The plants of varieties susquehanae occurs on acidic or neutralic soils, usually sand and rock barrens of the Appalachian mountains, and sometimes it is located on a wet lakeshores and marshes. It usually grows in open places and in open woods, sometimes entering forest areas $[1,3]$.

P. pumila "sensu lato" was first introduced to Russia at the beginning of the 20th century and var. pumila and var. besseyi, grown as part of the introduction collections of botanical gardens and breeding institutions $[7,8,9,10]$. The reason for this could be the fact that for the first time in the United States at the end of the XIX century. var. were involved in the introduction and selection. var. pumila as a stock and var. besseyi as a fruit plant [11].

A study of the presence and density of short pubescence in individuals of the introduction population can give an answer to the degree of participation in the formation of the gene pool of the introduction population of the Chelyabinsk region of the most distinctive susquehanae species. Representatives with this trait can increase the adaptive potential of the species under conditions of introduction.

\section{Methods}

The study was conducted on young branches of 197 randomly selected plants from the nursery of the company «Sad i ogorod» in the Chelyabinsk region.

The Hitachi TM-1000 scanning electron microscope (Japan) with original software was used to detect the presence or absence of short pubescence of twigs. The study was conducted at the collective use center of the Central Siberian Botanical Garden. A fragment of a dried annual shoot was pasted onto aluminum subject tables using double-sided adhesive tape (scotch tape). The image was taken at a magnification of $\times 50$ for photographing the general appearance of the twigs surface to $\times 1200$ for photographing details of the structure of hairs.

and tables, as originals of good quality and well contrasted, are to be in their final form, ready for reproduction, pasted in the appropriate place in the text. Try to ensure that the size of the text in your figures is approximately the same size as the main text (10 point). Try to ensure that lines are no thinner than 0.25 point.

\section{Results}

Continuous variability in pubescence intensity from bare branches to dense pubescence as a result of a study in the introduction population was revealed (Figure 1). 


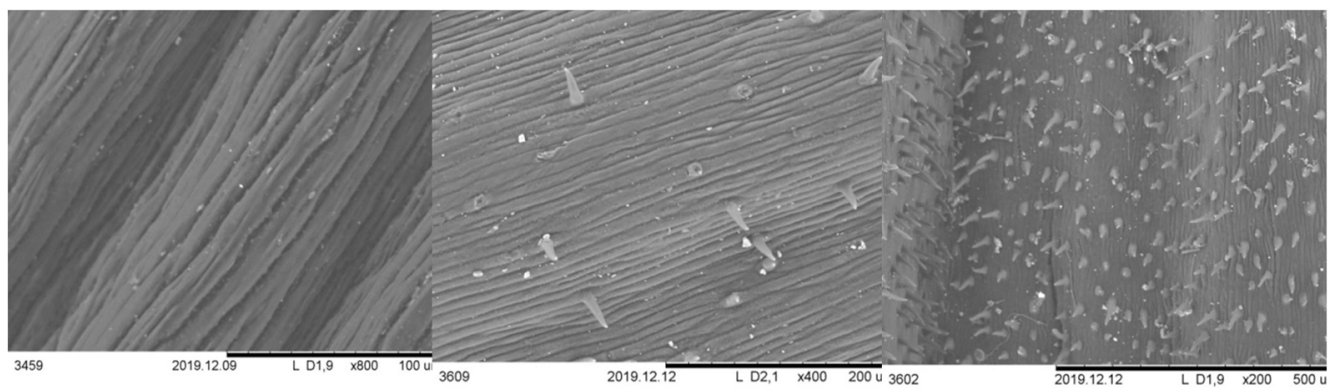

Fig. 1. Variability in the degree of pubescence of young twigs of different genotypes of the introduction population $P$. pumila.

Assessment of the degree of pubescence was carried out visually. If we arbitrarily distribute plants according to the density of trichomes in a well-visible area of $0.04 \mathrm{~mm}$ with an increase from $\times 200$ to $\times 800$, then the variability of this trait in the introduction population is presented in Figure 2.

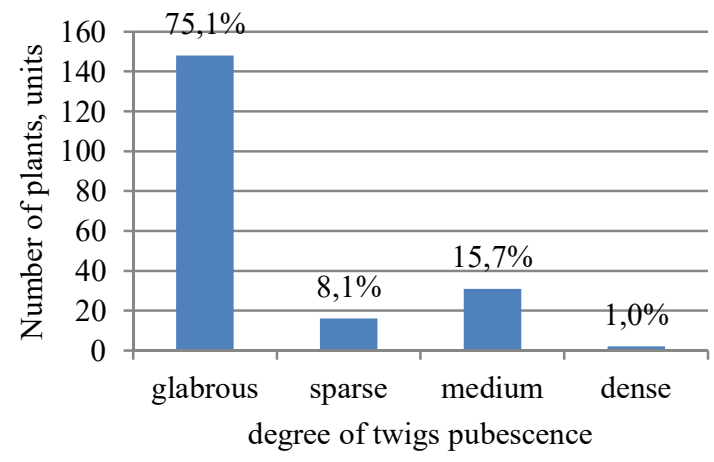

Fig. 1. Variability in the presence of short pubescence of shoots of the introduction population $P$. pumila. Note: rare pubescence - less than 7 trichomes in the area of $0.04 \mathrm{~mm}^{2}$, medium - with a number from 7 to 20 trichomes and dense - in the presence of trichomes more than 20 pieces per 0.04 $\mathrm{mm}^{2}$.

We compared our photographs of the short pubescence of young shoots of the P. pumila introduction population with photographs of Catling (1999) from susquehanae specimens; the trichome density of these specimens approximately corresponds to more than 20 pieces per $0.04 \mathrm{~mm}^{2}$. We have identified 2 genotypes with the desired trait - H 3-I-13 and H 3-I-6.

\section{Discussion}

Continuous variability in the number of trichomes on young shoots from bare shoots to densely pubescent in the studied introduction population of $P$. pumila was revealed. The revealed two genotypes with a density of trichomes of more than 20 pcs per $0.04 \mathrm{~mm}^{2}$ may be of interest for further introduction studies in regions with slightly acidic substrates, where at present this species is not cultivated successfully. Since this species is only found in wetlands in natural habitats, it is likely that isolated samples can be grown more successfully on poorly drained clay soils. The results obtained are of theoretical value in the development of methods for solving applied problems. 


\section{References}

1. P. M. Catling, S. M. McKay-Kuja, G. Mitrow, Taxon, 48, 483-488 (1999).

2. J. R. Rohrer, The Michigan Botanist. 39, 59-69 (2000)

3. J. K. Francis, Wildland Shrubs of the United States and Its Territories: Thamnic Descriptions, 1, 591-593. (2004)

4. A. S. Weakley, Change over time in our understanding the flora of the southeastern United States: implications for plant systematics, bioinformatics, and conservation (Duke University, Nicholas School of the Environment and Earth Sciences, 2005)

5. Flora of North America. (Oxford University Press on Demand, 2016)

6. M. Brand, Prunus x cistena 'UCONNPC001 .’U.S. Patent Application №15/731,338. (2018)

7. M. N. Salamatov, Cherry in Western Siberia (Novosibirsk: Publishing House of the Siberian Branch of the Academy of Sciences of the USSR, 1959)

8. V. S. Nizhnikov, Botanical Journal, 62, 533-536 (1977)

9. G. V. Eremin, A.A. Yushev, L.N. Novikova, Study of species of the genus Microcerasus Webb emend Spach in connection with their selective use in Proceedings on applied botany,genetics and breeding 65, (1979)

10. , A. B. Gorbunov, Introduction of non-traditional fruit, berry and vegetable plants in Western Siberia, (Novosibirsk, "GEO", 2013)

11. N. E. Hansen, Western sand cherry. South Dakota Experiment station, 87 (1904) 